\title{
Sudden cardiac arrest after coronary artery bypass grafting as a result of massive carbon dioxide embolism
}

\author{
Alan P. Kypson, MD, FACS, Greenville, NC
}

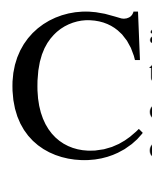

ardiogenic shock is a rare but potentially fatal complication of cardiac surgery. Numerous causes can lead to this outcome. Massive gaseous embolism leading to cardiac death is a rare but potential complication of endoscopic saphenous vein harvesting $(\mathrm{EVH}){ }^{1,2}$ A case of direct entry of carbon dioxide into the venous system of a patient undergoing EVH during coronary artery bypass grafting (CABG), resulting in hemodynamic collapse, is described.

\section{Clinical Summary}

A 43-year-old woman with no past medical history was seen with unstable angina. Nuclear stress testing revealed scintigraphic and electrocardiographic abnormalities in the anterior and lateral walls suggestive of left main disease. Catheterization demonstrated left main coronary artery spasm of $90 \%$, relieved with intracoronary nitroglycerin to $30 \%$. Despite calcium-channel blockers and nitrates, the patient continued to have symptoms, and a repeated stress test had positive results. The patient was referred to surgery.

CABG was performed with a vein graft to the left anterior descending and circumflex coronary arteries. Arterial conduits were not used because of competitive flow concerns. Vein was harvested with the VasoView endoscopic system (Guidant, Menlo Park, Calif). Carbon dioxide insufflation was initiated at a flow of $2 \mathrm{~L} / \mathrm{min}$ to obtain a pressure of $12 \mathrm{~mm} \mathrm{Hg}$. After separation from cardiopulmonary bypass, the VasoView system was reinserted with carbon dioxide insufflation to evaluate hemostasis. Subsequently, profound hypotension developed. Despite pharmacologic resuscitation, there was no improvement. Cardiopulmonary bypass was reinitiated. Numerous air locks were noted in the venous line. Transesophageal echocardiography (TEE) revealed a massive amount of "air" within the right side of the heart. The patient was placed in the Trendelenburg position. The VasoView system was removed, and the venous airlocks disappeared.

Once the patient was in stable condition with cardiopulmonary bypass, inspection revealed a torn saphenofemoral venous junction. This injury was oversewn. The patient was weaned uneventfully from cardiopulmonary bypass and discharged home in 5 days. At followup, she reported no angina.

From the Division of Cardiothoracic Surgery, The Brody School of Medicine, East Carolina University, Greenville, NC.

Received for publication Feb 9, 2005; revisions received April 30, 2005; accepted for publication May 3, 2005.

Address for reprints: Alan P. Kypson, MD, FACS, Division of Cardiothoracic Surgery, The Brody School of Medicine-Room 252, East Carolina University, 600 Moye Blvd, Greenville, NC 27834 (E-mail: kypsona@mail.ecu.edu).

J Thorac Cardiovasc Surg 2005;130:936-7

0022-5223/\$30.00

Copyright $\odot 2005$ by The American Association for Thoracic Surgery

doi:10.1016/j.jtcvs.2005.05.001

\section{Conclusion}

During the past decade, a paradigm shift in cardiac surgery has occurred. Endoscopic techniques with small incisions have replaced traditional, open techniques. EVH has decreased complications associated with open harvesting. ${ }^{3,4}$ Nevertheless, this technology carries its own set of risks. A report of 403 patients undergoing EVH demonstrated that $17 \%$ had carbon dioxide embolism, as documented by TEE. ${ }^{1}$ However, only 2 patients in that series $(0.5 \%)$ had massive carbon dioxide embolism. Two case reports of carbon dioxide embolism during EVH have also been published. ${ }^{2,5}$ One described a vein injury to a side branch of the saphenous vein; the other noted gas emboli during division of side branches. In both cases, pharmacologic interventions were successful in hemodynamic resuscitation, in contrast to our own case.

Mechanisms of carbon dioxide embolism involve absorption into the circulation or direct entry through an injured vessel. Because pressure gradients dictate the flow of carbon dioxide, arterial embolism during EVH is unusual. In contrast, a low-pressure system can be overwhelmed with insufflated carbon dioxide. Microembolization of carbon dioxide should be well tolerated because of the rapid and complete solubility of carbon dioxide. However, gross embolization may overwhelm this ability and cause devastating results.

Detection of carbon dioxide embolism is based on end-tidal carbon dioxide monitoring. If hypercapnia occurs, EVH should be suspended immediately and the femoral vein compressed. However, TEE is a more sensitive tool for detecting gas bubbles. ${ }^{1}$ Its routine use should result in early detection of carbon dioxide. Trendelenburg positioning, pharmacologic manipulations, and central venous pressure elevation by volume repletion should be implemented promptly, and the operation should be resumed with conversion to the open technique. In the case of a major embolism, direct aspiration from the right ventricle may relieve a gas lock. Obviously, if these maneuvers prove unsuccessful, emergency cardiopulmonary bypass may be required.

In this case, TEE monitoring had been discontinued. There was no evidence of hypercapnia on the end-tidal carbon dioxide monitor. Nevertheless, once the patient was placed back on cardiopulmonary bypass and continuous venous air locks were encountered, the unlikely complication of massive carbon dioxide embolism was strongly entertained. No attempts were made to aspirate intracardiac carbon dioxide because it readily resorbs. Discontinuation of insufflation and exploration of the groin confirmed the etiology of this patient's sudden cardiovascular collapse.

In conclusion, increased interest in novel technology for cardiac surgery will undoubtedly uncover previously unanticipated complications. In this case, an injury to the saphenofemoral junction created a portal of entry for insufflated carbon dioxide. Sudden cardiac arrest as a result of massive gas embolism ensued. Although there are numerous causes of cardiogenic shock in the perioperative period, it is important to keep in mind the less common ones. The surgical team needs to remain vigilant to prevent these technical issues from be- 
coming life threatening when treating patients with an abnormal perioperative course.

\section{References}

1. Lin TY, Chiu KM, Wang MJ, Chu SH. Carbon dioxide embolism during endoscopic saphenous vein harvesting in coronary artery bypass surgery. J Thorac Cardiovasc Surg. 2003;126:2011-5.

2. Banks TA, Manetta F, Glick M, Graver LM. Carbon dioxide embolism during minimally invasive vein harvesting. Ann Thorac Surg. 2002;73: 296-7.
3. Bitondo JM, Daggett WM, Torchiana DF, Akins CW, Hilgenberg AD, Vlahakes GJ, et al. Endoscopic versus open saphenous vein harvest: a comparison of postoperative wound complications. Ann Thorac Surg. 2002;73:523-8.

4. Davis Z, Jacobs HK, Zhang M, Thomas C, Castellanos Y. Endoscopic vein harvest for coronary artery bypass grafting: technique and outcomes. J Thorac Cardiovasc Surg. 1998;116:228-35.

5. Chavanon O, Tremblay I, Delay D, Bouveret A, Blain R, Perrault LP. Carbon dioxide embolism during endoscopic saphenectomy for coronary artery bypass surgery. J Thorac Cardiovasc Surg. 1999;118: $557-8$.

\section{Unusual chronic pacemaker infection by Mycobacterium tuberculosis in a pediatric patient}

Thomas Hellwig, MD, ${ }^{a}$ Phalla Ou, MD, ${ }^{a}$ Catherine Offredo, MD, ${ }^{b}$ Dorothée Stephany, MD, ${ }^{c}$ Damien Bonnet, MD, $\mathrm{PhD},{ }^{a}$ and Daniel Sidi, MD, PhD, ${ }^{\mathrm{a}}$ Paris, France

$\mathrm{P}$

acemaker infection with Mycobacterium tuberculosis has not been reported previously. We describe a case of pacemaker infection with M tuberculosis in an 8-year-old patient in a country in which tuberculosis is not endemic.

\section{Clinical Summary}

An 8-year-old patient had been followed up at our institution for a congenital cardiac malformation with a single-ventricle physiology. After multiple cardiac surgical interventions, an epicardiac pacemaker was implanted during cavopulmonary arterial anastomosis surgery for a complete atrioventricular block when the patient was 6 years old.

After a symptom-free interval of 11 months, the patient was seen with a subcutaneous abscess of the pacemaker site. The pacemaker was surgically removed, although only three of the four leads could be removed because one had integrated entirely into the myocardium. Bacteriologic cultures of the surgically removed material remained sterile. After 5 weeks of probabilistic intravenous antibiotic therapy, a new epicardiac pacemaker was implanted at a different site.

Six months later, the patient was seen with decreased general health, moderate fever, and inflammatory syndrome. A battery of blood cultures yielded negative results. Echocardiography did not find any evidence of endocarditis. While awaiting more specialized inves-

From Cardiologie Pédiatrique, ${ }^{\text {a }}$ Laboratoire de Bactériologie-VirologieParasitologie, ${ }^{\mathrm{b}}$ and Service des Maladies Infectieuses et Tropicales, ${ }^{\mathrm{c}}$ Hôpital Necker-Enfants Malades, Paris, France.

Received for publication April 4, 2004; accepted for publication April 21, 2004.

Address for reprints: Phalla Ou, MD, Service de Cardiologie Pédiatrique, Hôpital Necker-Enfants Malades, 149 rue de Sèvres 75743, Paris Cedex 15, France (E-mail: phalla.ou@nck.ap-hop-paris.fr).

J Thorac Cardiovasc Surg 2005;130:937-8

$0022-5223 / \$ 30.00$

Copyright $\odot 2005$ by The American Association for Thoracic Surgery doi:10.1016/j.jtcvs.2005.04.016

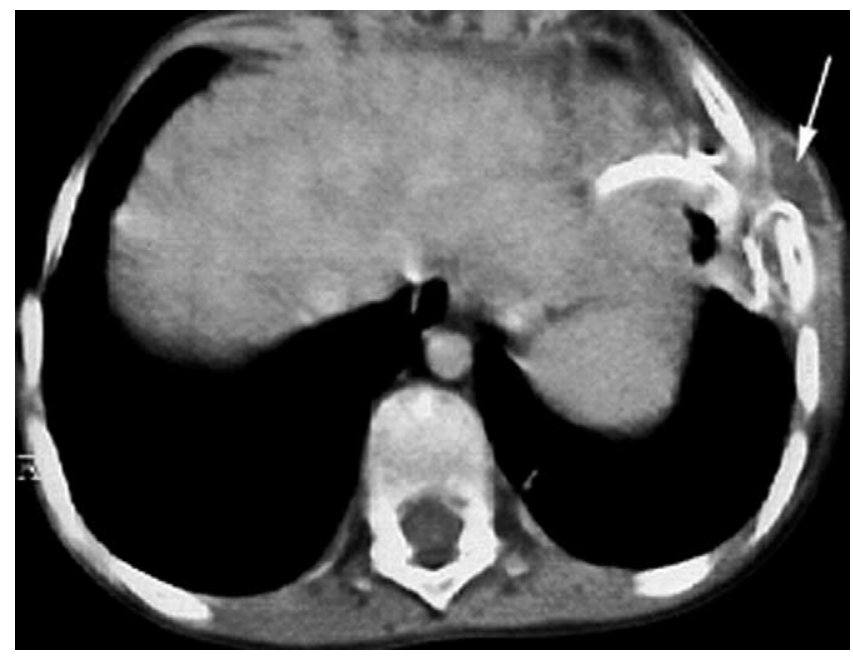

Figure 1. Thoracic computed tomography. Note soft-tissue abscess (arrow) containing pacing wires and inflammatory process following wire pathway.

tigations, we observed a subcutaneous lump above the new pacemaker site. The abdominothoracic computed tomographic scan (Figure 1) showed the typical aspect of a soft-tissue abscess, containing the pacing wires and accompanied by an inflammation following the wire pathway. After complete drainage and surgical ablation of the pacemaker, acid-alcohol-resistant bacilli were found on ZiehlNeelsen stain, and the diagnosis of $M$ tuberculosis was confirmed by IS6110-based polymerase chain reaction assay and by culture of the surgically drained fluid and pacemaker leads. The Mantoux test showed a positive reaction in the bacille Calmette-Guérin-vaccinated patient, who had never been in a country in which tuberculosis was endemic. Results of Mantoux tests and chest radiographs of the 5 